\title{
Equitable access to HIV counseling and testing for youth in developing countries: A review of current practice
}

Ann P. McCauley

Follow this and additional works at: https://knowledgecommons.popcouncil.org/departments_sbsr-hiv

Part of the Family, Life Course, and Society Commons, Gender and Sexuality Commons, International Public Health Commons, and the Medicine and Health Commons How does access to this work benefit you? Let us know!

\section{Recommended Citation}

McCauley, Ann P. 2004. "Equitable access to HIV counseling and testing for youth in developing countries: A review of current practice," Horizons Report. Washington, DC: Population Council. 
Equitable Access to HIV Counseling and Testing for Youth in Developing Countries: A Review of Current Practice

\author{
Ann P. McCauley \\ Horizons Program/International Center for \\ Research on Women
}

\title{
Hgrizons
}

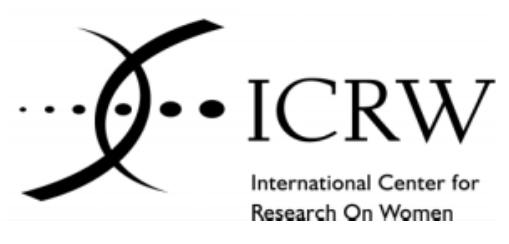




\section{Acknowledgments}

Several people have provided information and insight to this report. I would like to thank Milka Juma of Horizons/Population Council; Siobahn Crowley, Bruce Dick, and Jane Ferguson of WHO, and Julie Denison of Johns Hopkins University, for their comments on early drafts. The breadth of the report owes much to the discussion of this topic among the participants at the Consultation on the Health Services Response to the Prevention and Care of HIV/AIDS Among Young People, a meeting held by WHO, UNFPA, UNICEF, UNAIDS, and YouthNet in May, 2003 in Montreux, Switzerland. The Ugandan data are from a Horizons study conducted in collaboration with Edward Kirumira, Nelson Kakende, and Leonard Bufumbo of Makerere University, Kampala, Uganda.

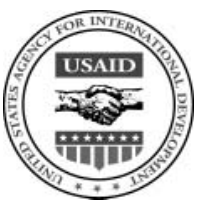

This study was supported by the Horizons Program, which is implemented by the Population Council in collaboration with the International Center for Research on Women, International HIV/AIDS Alliance, Program for Appropriate Technology in Health, Tulane University, Family Health International, and Johns Hopkins University. Horizons is funded by the U.S. Agency for International Development, under the terms of HRN-A-00-97-00012-00. The opinions expressed herein are those of the authors and do not necessarily reflect the views of the U.S. Agency for International Development.

Published in September 2004.

\section{(1) Population Council}

The Population Council is an international, nonprofit, nongovernmental institution that seeks to improve the well-being and reproductive health of current and future generations around the world and to help achieve a humane, equitable and sustainable balance between people and resources. The Council conducts biomedical, social science, and public health research and helps build research capacities in developing countries. Established in 1952, the Council is governed by an international board of trustees. Its New York headquarters supports a global network of regional and country offices.

Copyright $@ 2004$ The Population Council Inc.

Suggested citation: McCauley, A.P. 2004. "Equitable access to HIV counseling and testing for youth in developing countries: A review of current practice," Horizons Report. Washington, DC: Population Council.

This document may be reproduced in whole or in part without permission of the Population Council provided full source citation is given and the reproduction is not for commercial purposes.

Horizons Program/CDU Unit

4301 Connecticut Avenue, NW

Suite 280, Washington, DC 20008

Tel: 202-237-9400

Fax: 202-237-8410

Email: horizons@pcdc.org

www.popcouncil.org/horizons/horizons.html 


\section{Equitable Access to HIV Counseling and Testing for Youth in Developing Countries: A Review of Current Practice}

\section{Introduction}

Voluntary counseling and testing (VCT) for HIV infection is a process for providing individuals or couples with an HIV test. VCT consists of pretest counseling about whether to take an HIV test and what one's personal risks are for HIV infection. If the client decides to take the HIV test, he or she then receives test results during a posttest counseling session. Clients work with the counselor during the post-test counseling session to develop life plans for behaviors that protect themselves and others from HIV transmission and they receive referrals for needed services. While many people get HIV-related counseling and testing, only those who receive pre- and post-test counseling, and test voluntarily, are participating in VCT (see Appendix 1).

The high rates of HIV infection among youth make it crucial to find programs to prevent infection and mitigate the effects of HIV in this age group. Because there is evidence that many adults benefit from VCT (UNAIDS 2001; Weinhardt et al. 1999) there is increasing interest in extending these services to young people. VCT counseling aims to help adolescents evaluate their own behavior and its consequences. A negative test result offers the opportunity to recognize vulnerabilities and develop risk-reduction plans to adopt safe behaviors. Young people who test HIV-positive can receive referrals for care and have opportunities to discuss and understand what their HIV status means and what responsibilities they have to themselves and others as a result (WHO 2002). Young women who are pregnant and test HIV-positive should be offered special care to safeguard their own health and minimize the risk of passing the virus to the baby.

VCT services were designed when treatment for AIDS was not available in most of the world. Therefore, the original design of VCT services stressed the making of a personal plan with a provider as a way of motivating both people who were HIV-positive and HIV-negative to change their behavior in ways that would prevent their passing the virus to someone else or becoming infected. As initially planned, VCT services were focused on prevention of new HIV infections. Now that treatment is becoming more widely available, more health planners see VCT as a way of identifying those who need care. As the emphasis changes from prevention to care, less attention is being placed on the high-quality counseling that can motivate people to adopt safe behaviors and the usefulness of VCT as a preventive measure is being weakened.

This report assesses the available evidence about the current status of VCT and youth in developing countries. The report presents the available data to date on the impact of VCT among youth, what kind of services are needed, how policy and stigma affect access, and how VCT can be connected to other health resources, including care. At the end of each section, recommendations are provided based on the information presented. 


\section{I mpact of Voluntary Counseling and Testing on Youth}

To date there are no studies that have followed youth in the developing world to determine whether they reduce their HIV risk behaviors as a result of undergoing voluntary HIV testing and counseling. There are, however, such impact studies among adults in developing countries and among youth in industrialized countries (UNAIDS 2001; Weinhardt et al. 1999). Taken together, information from these sources suggests that VCT may be an appropriate and effective strategy for young people.

Studies among adults in developing countries report behavioral change after VCT on a range of indicators, including condom use, reduction in number of partners, and reduction in STI incidence. ${ }^{1}$ For example, a multi-center VCT efficacy trial in Kenya, Tanzania, and Trinidad found a number of changes due to VCT (Voluntary HIV Counseling and Testing Efficacy Group 2000). The trial had a randomized sample of 3,120 individual volunteers and 586 couples. Results showed that there was a significantly greater decline in the proportion of individuals who had unprotected sex with non-primary partners, among the group that received VCT as compared with the group that received a health education intervention. Also, HIV-infected individuals were likely to reduce sexual risk behaviors with primary partners and HIV-infected men were likely to reduce risk behaviors with non-primary partners as well. For couples, those who participated in VCT were significantly more likely to reduce unprotected intercourse with their enrollment partner when compared to those who received health education only. The study concludes that VCT is efficacious in promoting behavior change.

In fact, the populations for these and other studies already include youth because many youth are reached through programs intended for such populations as mothers, factory or mine workers, sex workers, drug users, or clinic clients. The high proportion of young people in many of the programs that have been successful in reducing risk behavior suggests that the youth in the VCT efficacy trial may be among those who changed behavior. Unfortunately the researchers who worked on the VCT impact study have not disaggregated their data by age, so it is not possible to see how VCT affected those in the study who were younger than 25 years old. This study of adult programs in developing countries does not tell us how effective VCT may be for young people.

Studies of VCT impact among youth in the United States do provide evidence that some youth adopt safe behaviors after testing. Although the U.S. studies often focus on high-risk individuals such as drug-users, runaways, and those in high-prevalence areas, they do look at the behavior of young people. Among these groups, several studies indicate behavior change (Table 1).

The combined evidence suggests that VCT may help youth in developing countries adopt safe behaviors. Eventually, of course, studies will provide more fine-tuned results, such as data indicating whether program effectiveness differs by service approach, test results, gender, marital status, kind of partner, and so on.

\footnotetext{
${ }^{1}$ WHO and the Johns Hopkins School of Public Health are currently compiling a review of the behavioral impact of VCT.
} 
Table 1 U.S. studies reporting behavior change among youth who underwent VCT

\begin{tabular}{|l|l|l|l|l|}
\hline Study and date & Location & $\begin{array}{l}\text { Study } \\
\text { population }\end{array}$ & Age & \multicolumn{1}{|c|}{ Findings } \\
\hline $\begin{array}{l}\text { Chamot et al. } \\
1999\end{array}$ & USA & $\begin{array}{l}\text { STI clinic } \\
\text { clients }\end{array}$ & $15-25$ & $\begin{array}{l}\downarrow \text { in gonorrhea among first- } \\
\text { time testers }\end{array}$ \\
\hline $\begin{array}{l}\text { Rotheram-Borus } \\
\text { et al. } 2001\end{array}$ & USA & $\begin{array}{l}\text { HIV- positive } \\
\text { youth }\end{array}$ & $13-24$ & $\begin{array}{l}\downarrow \text { unprotected sex, } \downarrow \text { \# of } \\
\text { partners, } \downarrow \text { substance abuse }\end{array}$ \\
\hline $\begin{array}{l}\text { Wenger et al. } \\
1992\end{array}$ & USA & $\begin{array}{l}\text { STI clinic } \\
\text { clients }\end{array}$ & $\bar{x} 23$ & $\begin{array}{l}\uparrow \text { in communication with } \\
\text { sexual partners about HIV }\end{array}$ \\
\hline
\end{tabular}

\section{Recommendations}

To meet research gaps for determing the impact of VCT on youth:

- Conduct research to confirm whether youth in developing countries adopt safer behaviors after VCT.

- Disaggregate data from existing VCT efficacy studies in developing countries to see the impact of the program on those under 25 years old in the sample. Such analysis should also document the impact on different kinds of youth - male, female, married, unmarried, younger, older, and so on-because each of these sub-groups of youth may react differently to VCT.

\section{Providing Services That Youth Will Use}

In many countries, young people actively seek VCT. The Kara Clinic in Zambia, for instance, reports an increasing number of youth seeking VCT, especially in the context of premarital testing (Chama and Kayawe 2000; UNAIDS 2002). In Uganda, approximately 15 percent of clients of the AIDS Information Centre (AIC) are between the ages of 15 and 19, and the number of young people (13 to 19 years old) using VCT in Brazil seems to be increasing. In Zambia, 15 percent of clients at the Hope Humana VCT site in Ndola are 10 to 19 years old. Forty percent of those attending the AIDS Testing Center (ATC) site in Bangkok, Thailand, described themselves as "students." In the U.S., 900,000 records of people who had undergone HIV testing were reviewed, and 13 percent of them were 13 to 19 years old (Boswell and Baggaley 2002).

Three studies provide insights into what barriers young people face in terms of seeking VCT. When adolescents (ages 12 to 19) in the Mpigi District of Uganda were asked what they thought of VCT services, many of the males and females were interested in HIV testing but concerned about confidentiality, the testing process, the accuracy of test results, and the cost of VCT services (Bohmer and Kirumira 1997). Privacy and service quality were also important to youth elsewhere. Among surveyed youth (14 to 21) in Kenya and Uganda, 41 percent of untested youth and 38 percent of tested youth reported that they would prefer to test at a youth facility rather than at an adult facility, where they might encounter adults they knew (Horizons 2001). Youth also wanted staff who are kind and who understand youth issues. Untested Kenyan and Ugandan youth wanted to be sure that they saw qualified staff who used reliable testing equipment. In Zambia as well, 
youth stressed the need for privacy in testing and the availability of complete and accurate information (UNAIDS 2002).

Youth want counselors who can give them accurate information in a friendly way. By "youthfriendly" young people mean that the counselor will not scold them for being sexually active or be judgmental about the young person's behavior (Juma et al. 2004c; Likwelile 2004). In two Ugandan clinics, tested youth participating in exit interviews rated the skills and friendliness of the providers as what they liked most about the VCT service (Figure 1). They mentioned long waits as what they liked least, and reported that the wait as each person received their results privately was a particularly stressful time (Juma et al. 2002; Kirumira et al. 2003). Assessment of services did not differ for males and females.

\section{Figure 1 Counselor characteristics that are "very important" to youth}

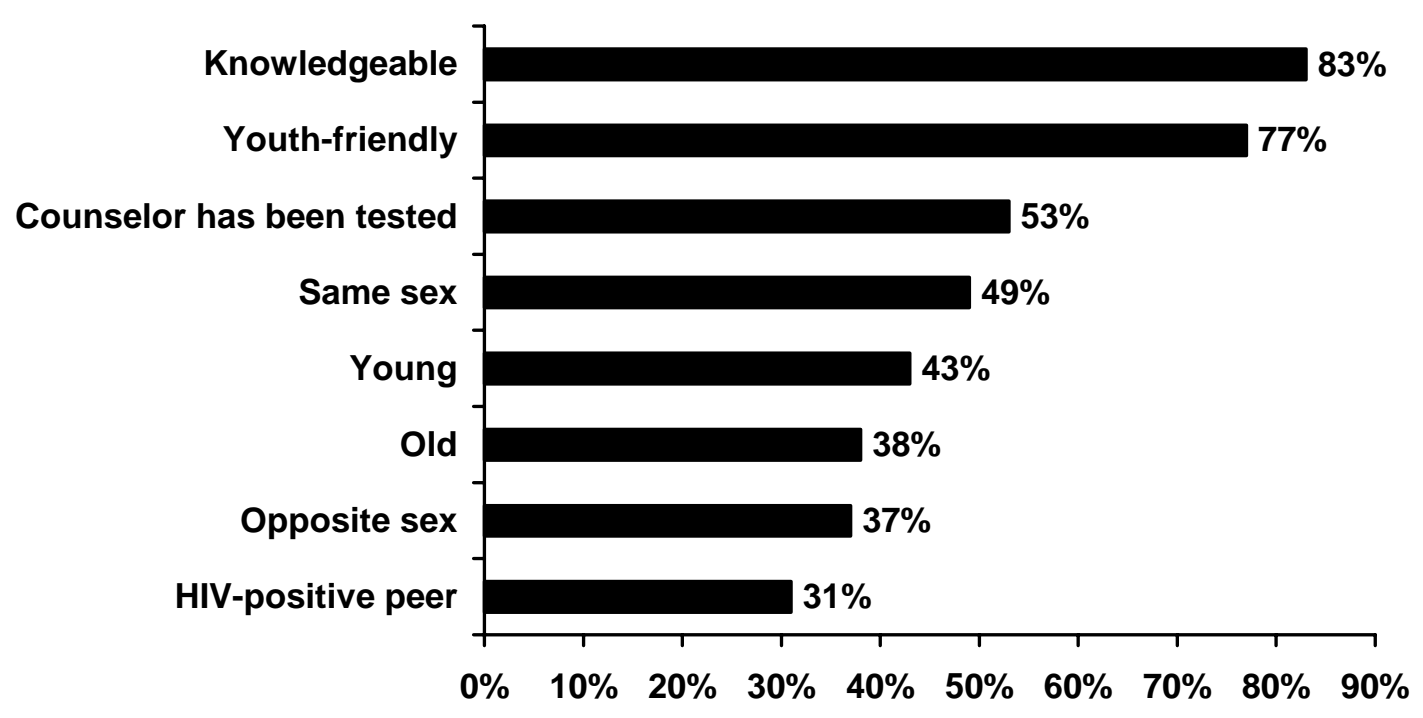

Source: Juma et al. 2004c

Counselors in Kampala reported that youth often think that counseling is tied to testing. Young people were not aware that they could receive counseling with the option of not taking an HIV test and therefore avoided VCT. In South Africa fear of coercive testing was so great that attendance dropped at health centers when they started offering the procedure to all ages (Boswell and Baggaley 2002).

Quality of counseling was also found to be a barrier to youth seeking testing. Although counseling is an integral part of the VCT process, HIV testing among Ugandan and Kenyan youth was not always accompanied by counseling (Table 2), and some youth could not remember discussing some key topics with counselors such as bringing one's partner to test or returning for a second test (Horizons 2001). 
Table 2 Youth exposure to counseling*

\begin{tabular}{lccc}
\hline Percent of tested youth who: & $\begin{array}{c}\text { Kampala } \\
(\mathrm{n}=86) \\
\%\end{array}$ & $\begin{array}{c}\text { Masaka } \\
(\mathrm{n}=49) \\
\%\end{array}$ & $\begin{array}{c}\text { Nairobi } \\
(\mathrm{n}=105) \\
\%\end{array}$ \\
\hline Talked to a health worker before taking the test & 90 & 84 & 72 \\
Received test results through counseling & 84 & 98 & 58
\end{tabular}

*This table is based on convenience samples of tested youth from selected sites.

Source: Horizons Program 2001

Counselor training and support are crucial to service success. Interviews and observations with 25 youth counselors in Uganda indicate that delivering VCT services to youth can be a stressful job. In addition to all the issues adult counselors normally face with clients, youth have some special issues as well. Many come to the service with multiple serious problems that the counselor cannot solve. Young clients also tend to be indecisive and highly emotional in counseling sessions. Counselors report frustration with youth, identification with the problems that youth present, and sorrow over having to give some youth the news that they are HIV-positive (Kirumira et al. 2002; Bufumbo et al. 2002).

\section{Service models that reach youth}

A recent WHO/UNAIDS meeting on VCT concluded that there is no single, ideal model of VCT service delivery because different approaches are required to reach different populations (WHO/UNAIDS 2001). This statement is true for youth programs as well as for adult programs. Program experience proves each service delivery approach will attract a slice of the population who need services. For example, in northern Thailand, VCT clinics see mostly men whose wives have already been tested as part of antenatal care (Kawichai et al. 2002). Sometimes it is hard to explain why one group uses a clinic more than another. For example, service statistics indicate that the Kara Clinic in Zambia sees more young men than young women and the AIC clinic in Uganda sees more young women than young men.

Confidentiality is clearly more important than setting. Adults and young people often do not seek VCT because they fear being seen at a testing site or having health care personnel tell others that they have come to be tested. For example, 2,400 individuals in Zambia were randomly allocated to receive VCT either at the local clinic or at an alternative location such as their home. Three times as many people accepted testing at the non-clinic locations compared to the

\section{Figure 2 Testing acceptance, by location}

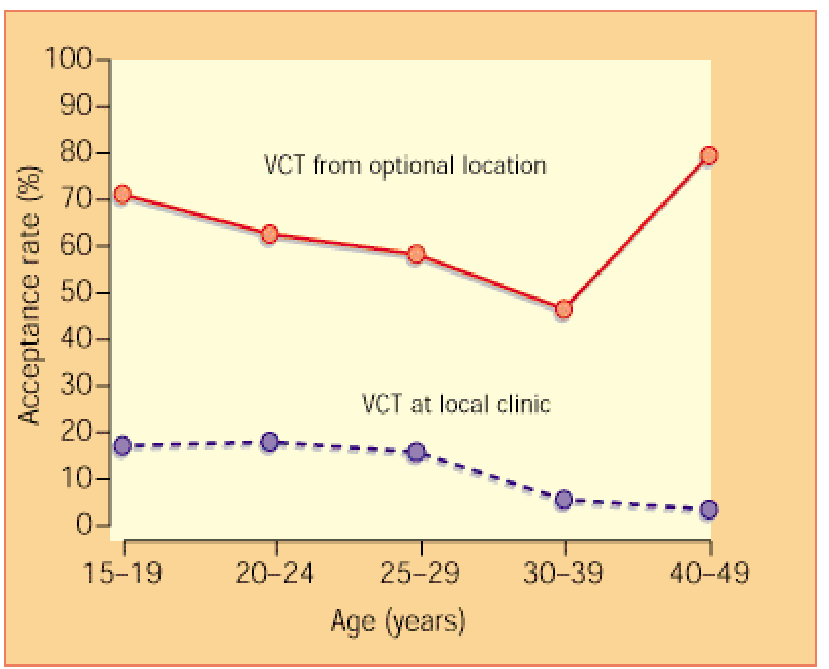


clinic location (Fylkesnes 2000; see Figure 2). The data indicate that a high percentage of youth were willing to be tested if they were offered testing in a private setting.

Various models of integrating VCT services into existing health structures have been implemented or suggested as ways to make these services available and accessible for youth. Boswell and Baggaley (2002) have presented a concise review of program experience to date. Building upon their work, a review of VCT service approaches for youth includes:

- Existing youth-friendly services. Since youth are often reluctant to use formal health services and reproductive health outreach activities do not usually target youth, integration of VCT services into existing youth-friendly services may be a viable approach. In Uganda, the popular Naguru Teenage Information and Health Clinic added VCT to its existing youth services in 2002 and got a very positive response. Attracting youth to services was far less of a problem for the clinic than such issues as sufficient space, enough personnel, and so on (McCauley et al. 2004a).

- Youth-friendly corners in primary health care clinics or youth-friendly corners in standalone testing centers. AIC in Uganda added a youth-friendly corner and more youth-friendly counseling in 2002. Youth expressed their relief that they did not have to wait or be counseled with adults. The service has attracted more females than males (McCauley et al. 2004a).

- School and college health care services. These services are already accessible and acceptable to youth and provide a good counseling location for some youth (Henry-Reid et al. 1998). There have not yet been any results indicating the effectiveness of this approach.

- Multi-purpose youth centers. Center Dushishoze in Butare, Rwanda, opened with youth activities and VCT services in January 2001 and was immediately successful in attracting youth. Because the clinic originally attracted many more males than females, special skills classes and activities have been added for girls (Boswell and Baggaley 2002). In this kind of setting, it would be important to emphasize issues like confidentiality, testing quality, and good referral networks for people who test positive. Some studies have shown counseling to be successfully integrated into youth culture within the U.S., through music and drama, and in some African settings as well (Stephens et al. 1998; Boswell and Baggaley 2002).

- Mobile services for youth. In 1990 Indian service providers started using a mobile clinic. Originally intended for high-risk groups such as sex workers, over time the mobile clinics have come to serve anyone who comes to one of the ten busy areas they visit each week (Yadav et al. 2002). Because of fear of stigma, many more people accept counseling than testing. There are youth-specific examples of mobile clinics from Uganda, Zambia, and Malawi, but such services are often focused more on targeting hard-to-reach populations rather than youth alone.

- Private care settings. Private health practitioners provide much of the primary care that is delivered in West Africa and Asia, and youth report that their chief sources of information and services are often pharmacists, traditional healers, and nurses in private practice (Kakande, 2002). Training private health practitioners to improve VCT services for youth may be a viable strategy, yet there has been little emphasis on these methods so far (Boswell and Baggaley 2002).

- "Booster" programs to extend program effect. AIC in Uganda, the Adolescent Counseling and Recreation Center in Kenya, the Kara Center in Zambia, and the Red Cross center in Thailand 
have all developed post-test activities for young people to help them maintain safe behaviors they have adopted as a result of VCT (Laibuta et al. 2002). Activities include recreation, skills building, and ongoing information sessions.

- Non-health settings: churches, schools, and other community settings. The Kibera Self-Help Project in Kenya offers VCT in a range of settings and has experienced a dramatic increase in people who came for testing. These services were provided for clients of all ages, not just youth (Marum et al. 2002)

\section{Strategies for serving more young people}

Two clinics in Uganda, the AIDS Information Center (AIC) and the Naguru Teenage Information and Health Clinic (NTIHC), learned that introducing services that youth liked attracted more youth than the clinics could serve (Kirumira et al. 2003). After training counselors from both facilities in how to provide youth-friendly services, the youth corner at AIC began operation followed by media promotion of VCT services through Straight Talk magazine and a local FM station, Radio Simba. NTIHC also started offering VCT services as a new type of service. These activities led to an influx of young people seeking VCT services at the two facilities.

The providers could not cope with the large numbers of young people seeking services. To avoid disappointing youth who might wait on the queue and later not be served, AIC booked only the number of youth they could handle each day and scheduled future appointments for the remaining youth (Kirumira et al. 2003). At NTIHC, where trained peer counselors were serving clients, the counselors determined that they could only counsel 20 young people each day, and so they served only the first 20 to come for VCT service each morning. To reduce counselor stress, NTIHC offered services only two days a week. Eventually the media outreach activities had to be discontinued to reduce the demand created by their promotional messages. In sum, the clinics needed more counselors and counseling rooms to handle the client load (Kirumira et al. 2003).

The Red Cross VCT centers in Honduras also use volunteer youth counselors to decrease cost and increase client satisfaction while maintaining a high level of service quality. The Honduran Red Cross, with assistance from the American Red Cross, has opened two VCT centers, one in each of the two largest cities of Honduras, which have one-half of all HIV infections (adult and youth) in the country. The centers receive clients at high risk for HIV identified through youth life skills counseling in homeless shelters and schools, deferred blood donors who test HIV+, and selfreferral. These centers use a unique system of voluntary youth counselors. The counselors are local university students studying psychology or social work. They are given a seven-day training program that includes modules on general HIV information, pre- and post-test counseling, use of rapid tests, crisis intervention, HIV stigma, and policies and procedures of the VCT center. Graduates of the course are required to work as volunteer counselors for one half-day session per week during six months of service in the VCT center. The voluntary work fulfills their university requirements for social service. The volunteer counselors give pre- and post-test counseling to clients. Although some of the counselors' parents were reluctant at first, the counselors also administer rapid HIV tests. Application of standard supervisory checklists has shown that the volunteer counselors perform all counseling and testing functions with adequate levels of competence. Additionally, exit interviews have revealed a high level of client satisfaction with services. The service is popular with youth and has reduced client costs. The program cautions that young counselors need clear instructions and that It can be difficult to offer services during university exam periods (Ricca et al, 2004). 


\section{Examples of program tools adapted for youth VCT services}

AIC in Uganda has developed and field tested a guide to youth-friendly counseling written especially for VCT service providers. The training course, based on their training curriculum for counseling adults seeking VCT, has been tested in three Ugandan and three Kenyan sites (Kyambadde 2003, personal communication). The training program requires counselors to complete the standard VCT counseling training program and then attend an additional three-day course on such youth-specific issues as adolescent development and concerns.

AIC, NTIHC, the Department of Sociology at Makerere University, and the Horizons Program have modified the UNAIDS VCT evaluation guide for use with young people. The adapted evaluation guide was administered to 369 youth at AIC and 399 at NTIHC as they exited services to determine their satisfaction. When their answers were compared to expert observations of the services, the answers indicate high accuracy of the young people's responses (McCauley et al. 2002).

In addition, there are several manuals for initiating, managing, and evaluating VCT programs for adults that can be adapted to serve youth. For example, Family Health International has produced a toolkit with separate modules for serving young clients, establishing a VCT program, commodity management, and counseling (www.fhi.org). UNAIDS has similar materials (www.unaids.org).

\section{Recommendations}

To provide services that youth will use:

- Focus on providing an intervention that ensures confidentiality and caring, well-trained counselors. When such services are available, youth use them.

- Provide a range of service approaches, including non-clinic testing locations, to reach different kinds of youth.

- Design services that attract youth who are at highest risk of becoming HIV-positive.

- Find low-cost approaches to meet the needs of the low-risk youth who come in for VCT.

- Provide "booster" programs such as post-test clubs to maintain safe behaviors and to give youth ongoing access to accurate information about HIV prevention and care.

- Avoid using "number of tests administered" as the principal measure of program success because this indicator might encourage providers to pressure young people who want only counseling to have HIV tests.

- Establish centers to train professional and lay counselors to provide VCT and youth focused counseling. Current data indicate that the quality of the VCT providers is crucial to the willingness of youth to attend. 


\section{Making Access to VCT Legal and Non-stigmatizing}

As with other health services, many countries require young people to be a specific age before they can agree to a medical procedure such as VCT without parental consent. This legal age of consent is often set at an age by which the majority of youth are already sexually active (see Table 5). In the high HIV-prevalence countries of Malawi, Mozambique, Tanzania, Zambia, and Zimbabwe, the legal age for consent to medical procedures is18, while in South Africa it is 14 (Boswell and Baggaley 2002; Crowley 2002). In these countries, counseling but not testing can be offered to youth under the legal age.

Table 5 Examples of age at first sex and age of consent for a medical procedure

\begin{tabular}{|c|c|c|c|}
\hline Country & $\begin{array}{l}\text { Median age } \\
\text { at first sex }\end{array}$ & $\begin{array}{l}\text { Age of consent for } \\
\text { medical procedure }\end{array}$ & Comments/Exceptions \\
\hline Brazil & $\begin{array}{l}\text { Males }=16.8 \\
\text { Females }=19.4\end{array}$ & $12^{* *}$ & $\begin{array}{l}\text { Health providers' discretion } \\
\text { accepted. }\end{array}$ \\
\hline Botswana & $\begin{array}{l}\text { Males }=\mathrm{n} / \mathrm{a} \\
\text { Females }=17.5\end{array}$ & $21^{\star \star \star}$ & \\
\hline Haiti & $\begin{array}{l}\text { Males }=17.2 \\
\text { Females }=18.9\end{array}$ & $18^{* * * *}$ & \\
\hline Kenya & $\begin{array}{l}\text { Males }=17.1 \\
\text { Females }=17.9\end{array}$ & $18^{* *}$ & $\begin{array}{l}\text { Married or pregnant youth; } \\
\text { counselor discretion for } 15 \text { to } 18 ; \\
14 \text { and under counseling only; } \\
\text { interview parents to protect child. }\end{array}$ \\
\hline Malawi & $\begin{array}{l}\text { Males }=16.5 \\
\text { Females }=17.0\end{array}$ & $18^{* *}$ & \\
\hline Mozambique & $\begin{array}{l}\text { Males }=18.3 \\
\text { Females }=16.0\end{array}$ & $18^{* *}$ & $\begin{array}{l}\text { Recently lowered to } 16 \text { for VCT } \\
\text { only. }\end{array}$ \\
\hline South Africa & $\begin{array}{l}\text { Males }=18.2 \\
\text { Females }=17.8\end{array}$ & $14^{* *}$ & $\begin{array}{l}\text { Same age for receiving ARV } \\
\text { treatment; court can give } \\
\text { permission for under } 14 .\end{array}$ \\
\hline Tanzania & $\begin{array}{l}\text { Males }=16.8 \\
\text { Females }=17.1\end{array}$ & $18^{* *}$ & \\
\hline Uganda & $\begin{array}{l}\text { Males }=18.3 \\
\text { Females }=17.3\end{array}$ & 18 & $\begin{array}{l}\text { Health providers' discretion } \\
\text { accepted. }\end{array}$ \\
\hline Zambia & $\begin{array}{l}\text { Males }=15.9 \\
\text { Females }=16.9\end{array}$ & $18^{* *}$ & $\begin{array}{l}\text { Girls who are pregnant or have a } \\
\text { child. }\end{array}$ \\
\hline Zimbabwe & $\begin{array}{l}\text { Males }=19.0 \\
\text { Females }=18.8\end{array}$ & $16^{* *}$ & $\begin{array}{l}\text { Youth with a sexual partner or } \\
\text { pregnant youth. }\end{array}$ \\
\hline
\end{tabular}

Recognizing that youth face a serious threat from HIV infection, Brazil and Uganda allow medical professionals to provide care to clients under the age of medical consent if the health provider deems such treatment to be in the best health interests of the young person (Crowley 2002; Josephine Kalule, personal communication, July 2002). In Kenya, where the legal age is 18, providers can deliver services to those 15 to 17 if the counselor determines that the young person is mature enough to consent to a medical service. Married or pregnant youth are considered "mature minors" and can be tested. 
The lack of clear policies around testing in many countries, coupled with the overall lack of clarity about providing youth with reproductive health services, places providers in a stressful position. A Kenyan study concluded that VCT services for youth need to be based on clear policies about testing, distribution of condoms to youth, and stigma and discrimination (Laibuta et al. 2002).

UNAIDS produced a policy statement on HIV testing and counseling in 1999 that can be used by national leaders to develop a national VCT policy (UNAIDS 1997). Although this statement does not refer to youth, it is a basic overall approach to ensuring that testing is voluntary, confidential, and of high quality. Subsequent UNAIDS documents have called attention to the need to provide VCT to young people and to other special populations (UNAIDS 2002).

In a recent meeting on access to HIV counseling and testing, the World Health Organization was given the responsibility to develop guidance on such policy and legal issues as age of consent and testing and provision of services for clients involved in illegal activities, such as sex work and drug use and such guidelines are forthcoming (Crowley 2002).

\section{Working with parents and the community}

Establishing services that satisfy youth, parents, and other community members requires working with all of these groups so that each group appreciates the concerns of the others. Often concerns conflict as for example when the parental restriction on testing seems intrusive to some youth but protective to many adults (McCauley 2004b).

A project in a Tanzanian refugee camps has successfully worked with all elements of the community to gain acceptance for youth who wish to test for HIV or use other reproductive health services. The International Rescue Committee (IRC) operates health services for Burundian refugees in camps in Kibondo District, Western Tanzania, under the umbrella of the United Nations High Commissioner for Refugees' (UNHCR) care and maintenance program for refugees. Initial assessments in 2000 found that, although many youth were sexually active, they did not come for medical treatment or support services due to negative and recriminatory attitudes toward adolescent sexuality on the part of health providers (Likwelile 2004).

The IRC designed a youth VCT program that reached out to the community in several ways. They offered services in a multi-purpose youth center that promoted youth participation in sports, drama and music and this diversity of activities reduced the stigma of youth who sought VCT for HIV/AIDS. Additional activities included: 1) using 60 peer educators to go into the community and inform them about the youth services and activities; 2) entrusting leadership of the center to the youth to plan and implement activities; 3 ) creating school health clubs; 4) using innovative media to publicize VCT and discussing cultural taboos via adolescent radio program; and 5) bridging gaps with parents and community leaders through involvement in debates, symposia, "parents day" celebrations, trainings and awareness workshops and by having them review all material before it was presented to the youth. In time the number of youth seeking VCT doubled and the communities requested additional centers (Likwelile 2004).

\section{Reducing the negative consequences of testing}

To make testing accessible to youth, programs need to reduce all the negative consequences for youth of seeking testing, not just the impact on risk behaviors. In Uganda, for example, many 
untested youth reported fearing that both medical staff and other clients would engage in stigma and gossip towards them if they entered a VCT facility, no matter what their results were (Kirumira et al. 2003).

To improve the provision of VCT, programs need to better understand to whom youth turn when making decisions about HIV testing. Supportive relationships may minimize the negative consequences of testing that youth fear including stigma and isolation (Juma et al, 2004b).

Some studies are examining young people's sources of social support when seeking VCT. In Zambia, qualitative in-depth interviews with 40 adolescents who had taken an HIV test, and 11 family members with whom they shared their HIV result, revealed that youth rely on their families and friends for support during VCT. Adolescents turned to their families, mainly parents and siblings, for permission and encouragement prior to seeking the service. Youth turned to their friends for detailed information about the VCT process and for company when going to the clinic. Half of the adolescents though, attended a VCT service by themselves citing fears of a positive result and a loss of confidentiality if anyone had gone with them to the testing site. After taking an HIV test, most youth shared their results with families and friends while few youth involved their sex partners in their testing experiences (Denison et al. 2004b).

Family members in Zambia expressed a variety of reactions to an adolescent's decision to test for HIV. Parents, who do not traditionally talk about sexual health, reported feeling a growing responsibility for educating youth about HIV by encouraging abstinence and VCT. While parents spoke broadly about HIV and sex, cultural roles influenced the kinds of information shared. For example, one mother said "I cannot tell my boy...that he must use condoms." Families felt that knowledge about a youth's testing should be kept within the family because they could "keep secrets" and would not expose the youth to gossip. Friends and others in the community might mock or embarrass the youth causing worry and, if HIV positive, potential death. This fear of stigma led family members to keep the youth's testing experiences a secret from outsiders but also to encourage other family members to seek VCT, and they advised the youth to re-test with future sexual partners. The decision to test was the young person's decision alone, and families encouraged but did not force youth to take an HIV test. Some family members felt that counselors could help HIV-positive youth disclose to their families, but most felt that youth should share their results unassisted (Denison et al, 2004a)

For many Ugandan youth, anxiety about emotional aspects of handling positive results was a major reason for not testing (Kirumira et al. 2003). Youth said that a positive test result might easily lead to negative social and psychological consequences. They mentioned that fear of stigma and discrimination from the community might force the positive person to move to a place where they were not known and that HIV-positive people might loose relationships have their intended spouse cancel a planned marriage.

Negative psychological outcomes resulting from positive results were considered common, even inevitable. HIV-positive people were thought to be unable to concentrate at school and work, and to be depressed because they could not hope to have a family or to make future plans. Such people might commit suicide or adopt a lifestyle filled with such risky behaviors as drinking and having many sexual partners. Others feared that the increased stress caused by learning that one was positive would exacerbate the disease (Kirumira et al. 2003).

VCT can indeed have negative results for some young people. Some young women tested at antenatal clinics in Burkina Faso, Tanzania, and Uganda expressed fear of physical abuse or abandonment after a positive HIV test (Maman et al. 2001; Nebie et al. 2001; Pool et al. 2001), and 
in Rwanda fear made younger antenatal clients much less likely to accept VCT than older women (Kowalczyk et al. 2002). In some cases, test results are used to decide whether or not to pay school fees for the young person, as protection from abandonment for young brides if their husbands become HIV-positive after the marriage, or as requirement on a school or job application (Juma et al. 2002; Siobhan Crowley, personal communication, May, 2003).

\section{Recommendations}

To make access to VCT legal and non-stigmatizing:

- Consult experienced providers about establishing a legal age for testing without parental consent that is based on the situations they have witnessed.

- Work with parents groups to promote testing for all family members.

- Document all the consequences, both positive and negative, of testing for young people. In counseling prepare youth to answer questions about being tested.

- Support programs that reduce stigma around VCT testing including programs they promote widespread testing.

\section{Connecting Testing to Care}

At a WHO meeting held in March 17-21, 2003, in Montreux, Switzerland, entitled "Consultation on the health services response to the prevention and care of HIV/AIDS among young people," participants felt strongly that there are ethical and practical reasons for strengthening the ability of programs to refer youth for other services. Most considered it unethical to provide testing without ensuring that the required treatment, care, and support elements were in place. Such services would include HIV-specific support and care, but not necessarily antiretroviral (ARV) treatment (WHO et al. 2003).

In addition, participants felt HIV testing might be a significant step in reducing stigma, if it is linked to and integrated with other elements of effective health care such as STI care, HIV care, antenatal care, or pregnancy prevention services. Testing for young people also clearly needs to be linked to other effective non-clinical interventions, such as rape counseling, post-test clubs, or community anti-AIDS clubs (WHO et al. 2003).

Few studies have looked at whether VCT connects young people to other health services or other HIV services, although it is clear that the programs could refer clients to preventive or palliative care (Kakande et al. 2003). One study based on a convenience sample of youth in Kenya and Uganda found that although some youth get referrals (see Table 6), most do not (Horizons 2001). The low number of referrals may be due to several factors, including youth not needing further care, lack of services to refer them to, or counselor error. Youth serving clinics in Uganda have put together a handbook of referral services for youth that is distributed to counselors who work with youth (Lukenge, personal communication, May, 2002). Studies that look looking at the effectiveness of referral systems for youth are needed. 
Table 6 Referrals of youth after VCT*

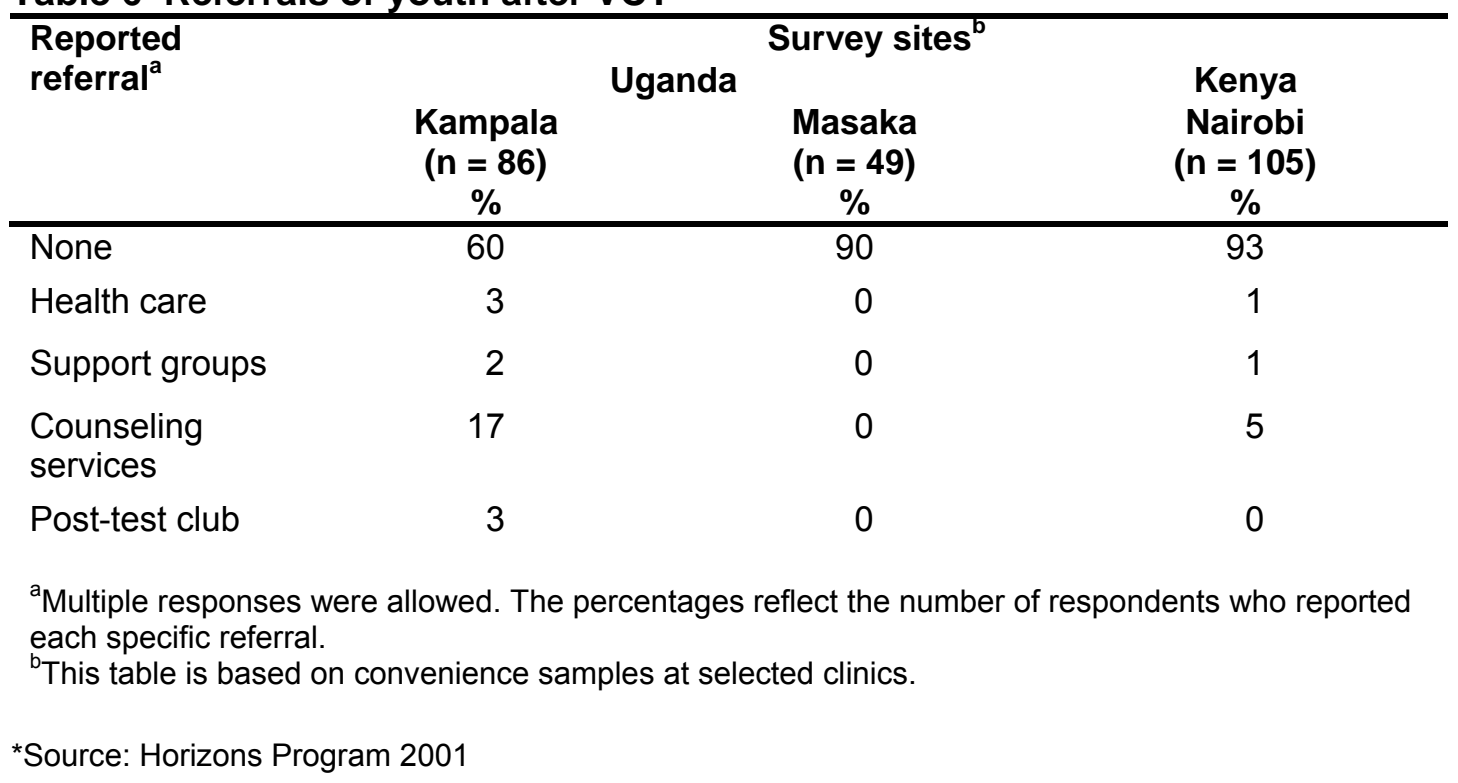

\section{Recommendations}

To better link VCT to care services:

- Develop referral networks to provide ongoing help to adolescents.

- Ensure that there are care facilities that serve youth well.

- Refer youth to specific individuals within other services. These individuals should have training and experience in working with youth.

- Establish a system by which youth can carry their records from one service to another so that they need not start over at each site.

\section{Conclusion}

VCT services for adults and youth are clearly changing as health programmers adapt them to new situations and circumstances. Despite such progress, youth continue to face barriers in accessing VCT services. These barriers will exist as long as judgmental providers do not respect the confidentiality of young clients and restrictive policies do not allow youth to test without parental consent.

VCT for youth should not lose the goal of promoting the adoption of behaviors that prevent the spread of HIV because most youth who test will not be HIV positive and are still in a position to protect themselves and others. Of those who do test positive for HIV, few will have progressed to having AIDS symptoms that require HIV treatment. They will also need to adopt preventive behaviors. Services for youth, as for adults, will need to increase their ability to refer clients to needed services for living with HIV. 


\section{References}

Bohmer, L. and E. Kirumira. 1997. "Final Report: Access to Reproductive Health Services Participatory Research with Ugandan Adolescents." Kampala, Uganda: Pacific Institute for Women's Health and the Child Health and Development Center, Makerere University, Kampala, Uganda.

Boswell, D. and R. Baggaley. 2002. "Voluntary Counseling and Testing (VCT) for Young People." Paper presented at the XIVth International AIDS Conference, July 7-12, Barcelona, Spain.

Bufumbo, L. et al. 2002. "Qualitative attributes in interpersonal relationship for VCT youth counselling." Paper presented at the Third International Counselors Conference, Sept 3-5, Nairobi, Kenya.

Chama, S. and I. Kayawe. 2000. "Sharing HIV Test Results with Future and Current Marriage Partners in Zambia," Sexual Health Exchange (1): 7-8.

Chamot, E. et al. 1999. "Gonorrhea Incidence and HIV Testing and Counselling Among Adolescents and Young Adults Seen at a Clinic for Sexually Transmitted Diseases," AIDS 13: 971979.

Demographic and Health Surveys. www.macroint.com/dhs/. Visited on May 15, 2004.

Denison, J. et. al. 2004a. "HIV Testing among Zambian Adolescents: What Role Do Families Have?" Paper submitted to NIMH Conference on the Role of Families in Preventing and Adapting to HIV/AIDS, July 21-23. Atlanta, Georgia.

Denison, J. 2004b. "Social Support for HIV Testing among Zambian Youth." Paper presented at the Global Health Council Annual Meeting, June 1 - 4, Washington, D.C.

Futures Group and YouthNet. 2004. "Parental Consent and Voluntary Counseling and Testing for HIV for Adolescents in Haiti." Draft document.

Fylkesnes, K. "Consent for HIV counselling and testing," The Lancet December 356 (Supplement 1) p 43

Henry-Reid, L.M. et al. 1998. "Youth counselled for HIV testing at school - and hospital - based clinics," Journal of the National Medical Association 90(5): 287-92.

Horizons Program. 2001. HIV Voluntary Counseling and Testing Among Youth: Results from an Exploratory Study in Nairobi, Kenya, and Kampala and Masaka, Uganda. Washington: Population Council.

Juma, M. et al. 2002. "Gender variations in uptake of voluntary counseling and testing among youth in Uganda." XIV International AIDS Conference. July 7-12, Barcelona, Spain.

Juma, M. et al. 2004a. Increasing youth satisfaction with VCT services in Uganda. Presentation at the XVth International AIDS Conference, July 11-16. Bangkok, Thailand 
Juma, M. et al. 2004b. "Social Support Networks and VCT: The Role of Partners, Peers and Siblings in HIV Testing for Ugandan Youth." Paper presented at the $2^{\mathrm{ND}}$ African Conference on Social Aspects of HIV/AIDS Research, May 9-12. Cape Town, South Africa.

Juma, M et al. 2004c. What kind of HIV counselors do youth want? Young clients speak out in Uganda. Poster presented at the XVth International AIDS Conference, July 11-16. Bangkok, Thailand

Kakande, Nelson. 2002. Accessibility and Utilization of Health Service: A Case of HIV Voluntary Counselling and Testing Among Ugandan Youth". MA thesis, Department of Sociology, Makerere University.

Kakande, N. et. al. 2003. "Strengthening Referral Systems as an Approach to Increase Accessibility and Utilization of VCT by Youth in Uganda." Paper presented at the International Conference on AIDS and STIs in Africa, September 21-26. Nairobi, Kenya.

Kawichai, S. et al. 2002. "Profiles of HIV Voluntary Counseling and Testing of Clients at a District Hospital, Chiang Mai Province, Northern Thailand, from 1995-1999," Journal of Acquired Immune Deficiency Syndrome 30 (5): 493-502.

Kirumira, E., C. Hitimana, and D. Lukenge. 2002. "Dealing with burnout in VCT for youth: Counselors' perspective." Paper presented at the Third International Counselors Conference, Sept 3-5. Nairobi, Kenya.

Kirumira, E. et al. 2003. "Youth and VCT in Uganda:," Presentation at the National Dissemination Meeting of the Youth and VCT Project. October. Kampala, Uganda.

Kowalczyk. 2002. "Voluntary counseling and testing for HIV among pregnant women presenting in labor in Kigali, Rwanda," Journal of Acquired Immune Deficiency Syndrome 31 (4): 408-415.

Laibuta, A. et al. 2002. "Youth friendly voluntary counseling and testing in Nairobi, Kenya." Poster presented at the XIVth International AIDS Conference, July 7-12, Barcelona: Spain.

Likwelile, Optatus. 2004 "Challenges in Voluntary Counseling and Testing for Youth: The Case of Karago Refugee Camp, Kibondo, Tanzania. Paper presented at the Global Health Council Annual Meeting, June 1 - 4, Washington, DC

Maman, S., et al. 2001. "Women's barriers to HIV-1 testing and disclosure: challenges for HIV-1 voluntary counselling and testing," AIDS Care 13(5): 595-603.

Marum, et al. 2002. "Rapid Increase in Utilization of Voluntary Counseling and Testing through a Comunity-Based Model in Kibera Slum, Nairobu, Kenya". Paper presented at the XIVth International AIDS Conference, July 7-12, Barcelona: Spain.

McCauley, A.P. et al. 2002. "Validating youth responses to UNAIDS evaluation tool for VCT services." Poster presented at the XIVth International AIDS Conference, July 7-12, Barcelona: Spain.

McCauley, A. P. et al. 2004a. "Attracting Youth to Voluntary Counseling and Testing Services in Uganda." Horizons Research Report. Washington: Population Council. 
McCauley, A.P. et al. 2004b. "Policy and Program Barriers Affecting Access to VCT Services for Youth" Oral presentation at the XV International AIDS Conference, July 11-16. Bangkok, Thailand

Nebie, Y. et al. 2001. "Sexual and Reproductive Life of Women Informed of Their HIV Seropostivity: A Prospective Cohort Study in Burkina Faso," Journal of Acquired Immune Deficiency Syndrome 28(4): 367-72.

Pool, R. et al. 2001. "Attitudes to Voluntary Counselling and Testing for HIV Among Pregnant Women in Rural Southwest Uganda," AIDS Care 13(5): 605-15.

Ricci, J., J. Duron, and E. Vinelli. 2004. "Volunteer Youth Counselors for HIV Voluntary Counseling and Testing". Paper presented at the Global Health Council Annual Meeting, June 1 4, Washington, DC.

Rotheram-Borus, M.J. et al. 2001a. "Efficacy of a preventive intervention for youths living with HIV," American Journal of Public Health 91(3): 400-5.

Rotheram-Borus, M.J. et al. 2001b. "An intervention for parents with AIDS and their adolescent children," American Journal of Public Health 91(3): 1294-1302.

Stephens, T., R.L. Braithwaite, and S. Taylor. 1998. "Model for Using Hip Hop Music for Small Group HIV/AIDS Prevention Counseling with African-American Adolescents and Adults," Patient Education and Counseling 35(2):127-137.

UNAIDS. 1997. "UNAIDS Policy on HIV Testing and Counseling." Policy statement. Geneva, Switzerland.

UNAIDS. 2001. "The Impact of Voluntary Counseling and Testing: A Global Review of the Benefits and Challenges" UNAIDS Report. Best practice Collection, Geneva, Switzerland.

UNAIDS. 2002. "HIV Voluntary Counseling and Testing: A Gateway to Prevention and Care." UNAIDS Report. Geneva, Switzerland.

Voluntary HIV Counseling and Testing Efficacy Study Group. 2000. "Efficacy of voluntary HIV-1 counseling and testing in individuals and couples in Kenya, Tanzania, and Trinidad: a randomized trial," Lancet 356 (July 8): 103-112.

Weinhardt, L. et al. 1999. "Effects of HIV Counseling and Testing on Sexual Risk Behavior: A Meta-Analytic Review of Published Research, 1985-1997," American Journal of Public Health 89 (9): 1397-1405.

Wenger, N.S. et al. 1991. "Reduction of high-risk sexual behavior among heterosexuals undergoing HIV antibody testing: a randomized clinical trial," American Journal of Public Health 81(12): $1580-5$.

Wenger, N.S. et al. 1992. "Effect of HIV antibody testing and AIDS education on communication about HIV risk and sexual behaviour: A randomized, controlled trial in college students," Annals of Internal Medicine 117(11): 905-11. 
World Health Organization/UNAIDS. 2001. Technical Consultation on Voluntary Counseling and Testing: Models for Implementation and Strategies for Scaling of VCT Services. Report of Meeting held July 3-6, 2001 Harare, Zimbabwe

World Health Organization. 2002. "Increasing Access to HIV Testing and Counseling." Report of a WHO Consultation, November 19-21. WHO: Geneva, Switzerland.

World Health Organization et al. 2003. "Global Consultation on the health services response to the prevention and care of HIV/AIDS among young people: Accelerating country level action." Technical Report of a Consultation, March 17-21. Montreux, Switzerland.

Yadav, S. et al. 2002. "Multipurpose mobile HIV clinic- becomes a replicable model of care for large towns in resource-poor settings." Poster. XIV International AIDS Conference. July 7-12, Barcelona, Spain. 


\section{Appendix 1}

\section{The Process of Voluntary Counseling and Testing}

Voluntary counseling and testing is the process by which an individual undergoes counseling enabling him or her to make an informed choice about being tested for HIV. This decision must be entirely the choice of the individual and he or she must be assured that the process will be confidential (UNAIDS 2001).

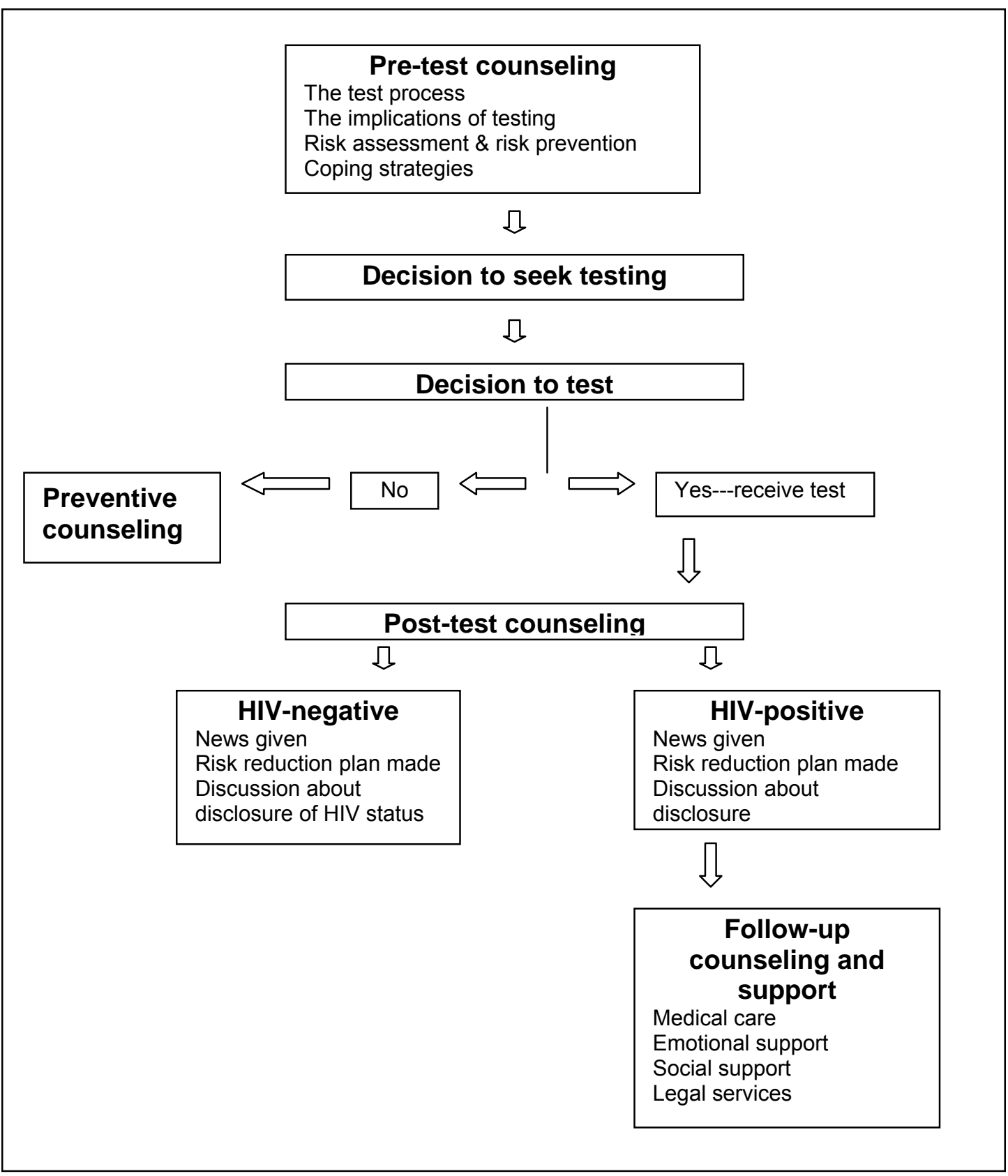

